\title{
On the practice of inquiry learning method in museum children's education
}

Tao Tingting

( Nanjing Museum,Jiangsu Nanjing 210001)

\begin{abstract}
There are outdated ideas in the education of museum children in China 、Preaching indoctrination 、 Similar content 、 Lazy in innovation and so on Problem,Difficult to attract children to enter the museum to explore and study.So,This paper puts forward the introduction of inquiry learning method into museums. Advice on child education,Introduce the concept and characteristics of inquiry learning method, The necessity and key of analyzing and practicing inquiry-type learning method Point,Some ideas on the design of inquiry learning content.
\end{abstract}

Keywords:Research-oriented learning method; Museum; Children's Education; Educational Practice

Middle Figure category Number: J0 Document Identification Code: A

American Museum expert George E. Hein( GEoRGE E. HEIN) professor in with as 《Learn in Bo Objects Pavilion 》 ( LEaRNING IN THE MUSEUM) a book Medium,proposed the Four Museum education modules : TeachGuided Solutions say type、Thorn excitation - reaction type、Discovery type、 Build Construct Knowledge type. [1] 22 The construction knowledge is also called probing type. The theoretical basis of exploratory learning learning is to construct the main semantics, This theory to,Knowledge get constructed ,instead of subject Transfer 's,Building Knowledge is human Day of Class Sex,people Total is a constructed party( that applies existing knowledge through Test) to recognize recognize and understand him the reality of the world boundaries. [2] 11 Constructivist learning theory research what people are like the nature of what learning and Rules Law,Inquiry-based Learning based on this theory legal value to Museum educators Research and practice practise.

One、 What is inquiry learning method

constructivism Change Change Traditional Teaching View,it think learning is not simple is knowing knowledge from outside to inside Transfer and pass Pass, It is the learner who actively constructsthe own know experience process, [1] 23 ,This is also the core psychology of inquiry-based learning methods Read.in Explore research learning, learners according to their own Hobbies or studies XI Service,Choose Learning within boundary environment allow,make Experience and Exploration Lasso,through the new experience and original have know Experience repeated bidirectional interaction with [1] 23 ,Add Plus、 Enrich your knowledge read through ,Implementing learning Goals superscript.probing investigate Type Learning Special Point has two main sides face: (1) students are the leading of learning who,His initiative is the driving of learning Force; (2) Analysis

Study-oriented learning is a learner's interaction with the outside environment,So,Outside The creation of environment is very important to inquiry learning.

\section{Copyright (C)}

This is an open-access article distributed under the terms of the Creative Commons Attribution Unported License

(http://creativecommons.org/licenses/by-nc/4.0/), which permits unrestricted use, distribution, and reproduction in any medium, provided the original work is properly cited. 
Two、 The necessity of practicing inquiry learning method in museum children's education

Mesh before,Museum children teaching in China Fertile hair exhibition,But there are some Ask title.from A study of the Customs to Look,main question The problem is educational activities 's insidecapacity.List two representative here Comments described: "Preaching Stuff too more,inspiring things to create too less, 'Fill Duck' Teaching ways are often filled with educational activities for minors in museumsMedium.” [3] 42 “Many museums are just for education to live Move, while blindly referencing his pavilion active content and shape style,Some even end full photo move,failed Sudden out of the library's specialColor,Difficult long-term dimension hold,brand more impossible talk up." [4]73 This is not difficult to send now,Concept Chen Old、Sermon Irrigation lose、Content Thunder same、 Lazy in innovation and other causes of poor education Q questions,All Education Activities the contents of the Have off. Imagine Next,how can such content inspire children's interest in learning ??

Trace,Since it is educating children,Museums should consider the needs of children What kind of learning experience.At school, The purpose of children's study is to test,Has Mandatory,They can't choose what to learn. 、 How to learn.And the study of museums belongs to Informal learning,Children have the right to choose,If the contents of this study 、 Way to Meet their needs., They'll be actively involved.,Otherwise,Museum The educational activities of the museum can only become a chicken.From the nature of children, They were born

* About the author: Tao Tingting(1976 — ）,Woman,Chinese,Jiangsu Nanjing People,Nanjing Museum Librarian.Research direction: Research on the Theory of public culture,Museum education.

Curiosity and thirst for knowledge,As long as there is a suitable environment and conditions, They'll be happy. This is not exhausted to explore,To satisfy one's own curiosity,Accumulate knowledge and experience at the same time. Through the understanding and analysis of inquiry learning method,We found it to be a Learning methods that coincide with children's nature.If you explore in the museum -Type Learning method,Create a different learning environment from the school,Must be able to inspire children

Children's interest in learning.

Three、 The key to practice inquiry learning method in museum children's education

Children's initiative is the driving force of inquiry, Their initiative stems from good The heart and the interest,Only the learning content itself is attractive,Children's curiosity and Interest can be stimulated.Can say,Learning content is the prerequisite of inquiry.Because This, The key to practice inquiry learning method in museum children's education,is educating people Designed for children to explore learning content.If a child is at a museum show Overview 、 Activities attracted,will be actively involved.,Actively explore,Accumulate experience and Knowledge.However,The design of learning content is the general Not good at,So it should be used as a breach of work.Learning content Design The basic idea is,Combing the educational resources of museums、Integration、Decomposition、Create For,Turn them into forms that benefit children, Construct children learning Ring .

Four、The concrete method of designing inquiry learning Content

The author based on the characteristics of inquiry learning and its own work experience,to explore Some ideas on the design of the content of sex learning.

\section{Using Divergent thinking,Discover rich and deep learning content Museum exhibitions are usually made around a theme, will be a certain number}

Amount of artifacts according to time、Use、Type of order display,supplemented by the corresponding text Word description 、 Scenarios and multimedia effects.Most of the exhibitions are basically for ordinary For adult audiences., Which contains a great deal of history、 Text background and heritage letters Interest,It's hard for children to 
read.Educational personnel should use divergent thinking,From the exhibition Digging rich and deep content,Reprocessing 、Creation,In the form of educational activities Output,To make children interested and understand.

The human mind is divergent,,Divergent thinking can bring people a wide range of vision, Is the source of innovation.Although the ability of divergent thinking is weak,But you can To be promoted by practice.Divergent thinking can help educators discover exhibits The pluralistic relationship,Like a piece of porcelain., Can be from its owner、System author、Of Present person、An analysis of the viewer's perspective,You can also show it with the age of the Society 、 Economic 、 The link between cultural backgrounds, You can also compare it to a variety of related artifacts , The learning content designed on this basis has the value of inquiry..

"Understanding Extension slices” is a regular education in my library Move,Original this is done as Main, more Single Tune.where educators use divergent thinking sides Method,Heavy New RecognitionKnowledge “Rubbings” , from the concept of rubbings out Send,Migrate to it from Source、producer Method、Send exhibition、should with 、 related Exhibitions product and its links to modern people, etc. multiple layers face, Then and Select take 、 in-organization capacity.New Live Move not only content Rich,more child discovery Ring Section,Such as: View Watch

“Royal Pavilion Stone Stele” ,speculate rubbings Path; tothan physical and its photos and extension movie,Discovery rubbings Point; in Showroom look for artifacts to record information with rubbings etc.in New Activity Medium,Child Autonomy Observe、Think test、Manipulate make,Right“extension slices”has a full face、Deep Recognition Knowledge.

2. Using stories to create an exploratory situation

Storytelling is a human tradition..In Primitive society,People use dictation to record

Things 、 Transfer experience,After the text appears, The way stories spread from word of mouth Transition to written records, The revelation of the story to human education The role of no alternative. The preservation of the human heritage in the museum contains a wealth of stories., If you use a story Helping children to understand the heritage of their ancestors, Obviously, it's perfect..

Educators tell stories to children,Weave the artifacts into the story,Will isolate Cultural relics are associated with all kinds of people and things.,can help children to put unfamiliar cultural relics withConnected to their own knowledge and experience,Make it easier for them to understand the heritage of information.Storytelling also creates a vivid context for children,Let them in Rich Associations in the story、Bold speculations and positive verifications, In the latent movement Autonomous learning in the process of.

Nanjing Museum of Natural History Pavilion 《Dragon Pan Tiger Squat — — — Nanjing City History》 exhibition Medium,Display some money for different times currency,Educating People The member is explaining the topic when,Change original has square style,tell a small audience about coins first things.From "ancient times currency out now”,To“Beta Currency gradually metal goods Currency substitution”,then to “All periods goods currency change ”,to Concatenate for Threads things.Hear me Out things,small audiences have been to ancient Calendar for currency History 、 with Path 、 features such as A general recognition Knowledge.this when,Teach the fertility personnel to ask questions lead guide children to think test,Such as: “Why shells can be goods Currency?” 、 “PayPal Why Metal Currency Generation?" thenthe,ask them to touch the money . Currency Copy Product,View two different periods of money Currency,want think of them in the material Quality - like、 text Word vattern , and so on DifferencesWith.inThis activity Medium,The story attracts child child's attention Force,Bring them rich Sense subject,help them deeper Understanding Learning Learning content.

3. add explanatory content to the exhibition and experience the text of the event exhibition Word、Figure Table、 Scene Duplicate Original、Shadow like capital Material、Multimedia interactivity

It's an explanation of the exhibition.,Due to the limited capacity of the exhibition and the form design Need,Limited number of Explanatory notes.Furthermore,The audience of the exhibition is generally defined as the general through the adult audience ,So,It explains the inability to meet the needs of children's visits.. Educators can 
design interpretative content specifically for children 、Increase the experience of living Moving Way,Provide more material for children's exploratory activities.Because of this kind of interpretation Sexual content and experiential activities are complementary,and only for children,So should haveRich content、Simple、Flexible、Save space and other features.

Japan Museum 's Heritage Display instructions follow people-oriented original then, do the allow viewers to read through,such as Chen Lietau Knife,will be attached next to A simulation that enables to harvest cereal with a ceramic knife slice; Display Horse With ,The will be accompanied by a Zhangquan set prepare horse recovery diagram. [5] 48 this use diagrams to abstract content images format、 The With body method is worth borrowing check.Naturalist the exhibits in the pavilion often contain many abstract letter ,Difficult for children to Look directlyUnderstand.If educators are special do not design for children Hand-Flip Figure Relieve yourself Book,The discovery of the exhibits condition、 Times back King、Use square method、with other text Objects relationships and other information to imageformat 、 materialized Ming,The children can see the show view ,Side Lookup Diagram Solution,Read Exhibitions autonomously .

Smithsonian national United States Calendar Museum of History more in place Car "Interactive Hand Push Car” , Instructors in Keep in Next,Help the audience touch the hand Touch "Calendar history" ,Connect Touch History Object Item,inside the study hall 's Hide Product.Specific Package Enclosed: teach you how to manipulate the milk wool Machine、such as what observe stereo Mirror、Body Wear tight Chestclothes 、 How to print machine to print cards slices,and try to copy a book in a way that is used by the lame when it's been in use in the last year Letter. [6] 205 This a procedure is also worthwhile Ito borrowForensic.children through direct experience Way to learn XI,He's like fresh have fun EastXi.and Museum standing experience projects are not more, in basic display capacity Long term notChange,lack of absorption of children Primer Force.Educators can mining with "Interactive Hand Push Car" Shape style,Change experience items regularly Mesh,let children in exhibition Hall

You can always take a look at it. Touch、Listen to、Smell、Try,In play Explore.

4. “Questions” That inspires wisdom.,Educators should pay attention to "Questions”, Not Encourage children to ask questions,Discovering children's unique perspectives and points of interest,Also Be good at using questioning skills, Guide children to think and discuss.

to in children Garden、Child in primary school Child,educators can pass "Ask” guide them Learn Learning View Observe.Example such as: let children compare exhibits with different same,distinguishbetween the same and the same kind of exhibition product,Description Exhibition Fine Product Section,by Exhibit features guess guess what it's used for etc..for children say,View by yourself learned KnowledgeKnowledge, Deeper Impressions Engraved.

for primary school seniors Child Child,Teach Yukon can pass “mention Ask” Drum excitation them to think more test.in view before,First to Small Audience Release work Hand Book,let him take a question tothe view,Show Yourself Look for answers Case.Attention Required Yes,In learning from museums in,The purpose of the question to cause a thought Test,and not only get to correct answer case,as long as childrenView Observe、Body Test、Move Brain ,is worth the drum excitation.Parameter view end after,educate people to organize students discuss work manuals together Q title,Every person elaborates from own 's wantMethod.in this procedure Medium,Educating People A member can mention it in a timely manner Ask,Help children complete rationale、 Expand Thinking Road,Such as: "which details in the exhibit show sixthe period of Buddhism in the dynasty Sheng?"; “Original Pottery appears after,People's lives have happened which changes To ?" ; “If you is this historical person Objects, You what happens do?" And so on wait. Children in light Pine、Happy Thinking in open discussion Test,the gets more than know ,and Speculative Energy Force、 Fun to explore Interesting. 
The inquiry learning method respects the child's nature,Conform to the cognitive law of children,And Compared with traditional learning methods,It can inspire children's learning enthusiasm,Develop children Learning ability and scientific accomplishment.The museum has very rich learning resources to and the educational environment suitable for inquiry,So it is the best for children to study Place.The museum should be duty-bound to take up this responsibility,Exert oneself advantage,Invasive Making conditions,Attracting children to learn and explore freely.

\section{References}

Chanche Meta. Beauty Science and technology Museums and science teach education [J]. Science Research Study investigate,

2007, , ( ).Z

2. Zhongzhi Yin. Build Constructivism learning theory and teaching design Count $[\mathrm{J}]$. Audio-visual Education Research investigate,2006,( 05) .

3. Xu Ning. set to Xiang Order School with Teach,more knowledge of animals and birds name - — - South through Museum of History example on Museum Children's Education show [J] . Museum Researchinvestigate, 2015 , (02).

4. Yangdan Dan. on the availability of museum education activities continued exhibition ——— to the capital Bo things Museum Youth education activities for example [J] . China Museum Pavilion,2010,( 01) .

5. von Hui. Bridge between archaeological and mass communication Beam——— to Osaka Museum of History to Example [J]. Popular Test Ancient,2014,(08) .

6. Zheng Game. Museum education Activities Research investigate-——Audience Visiting Museums before、In、 Post -planning for three-stage educational activities and real shi [D]. Dr. Fudan University degree on text,2013. 